\title{
Acidentes perfurocortantes entre acadêmicos de Odontologia
}

\begin{abstract}
Fernando Antônio Pontes Castro*; Antônio Joaquim de Brito Júnior**; Carlos Alberto Monteiro

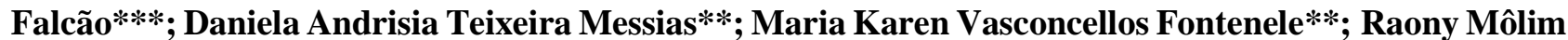
de Sousa Pereira***; Ronaldo Carvalho Pinto Almeida**; Maria Ângela Arêa Leão Ferraz***
\end{abstract}

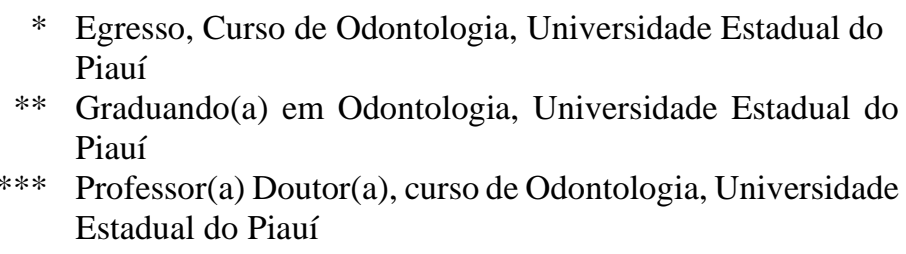

Recebido: 14/04/2020. Aprovado: 10/04/2021.

\begin{abstract}
RESUMO
Os profissionais da saúde estão expostos aos mais diversos riscos ocupacionais durante a sua jornada de trabalho e os cirurgiões-dentistas lideram o número de acidentes com materiais biológicos. Os atendimentos por acadêmicos de odontologia os deixam expostos aos riscos ocupacionais de forma semelhante aos profissionais da área. Este estudo teve o objetivo de avaliar prevalência e características dos acidentes com instrumentais perfurocortantes entre os acadêmicos de um curso de Odontologia. Constatou-se prevalência de $28,85 \%$ de acidentes, com o maior percentual no $5^{\circ}$ período de curso, principalmente nas clínicas de Cirurgia e Endodontia. Apenas 20\% dos afetados relataram a ocorrência e a sonda exploradora foi o instrumental mais envolvido. Além disso, os acidentes ocorreram de forma igual no atendimento ao paciente e lavagem do instrumental. Portanto, faz-se necessário investimento em ações educativas e normativas permanentes para conscientização de acadêmicos sobre acidentes perfurocortantes.
\end{abstract}

Descritores: Estudantes de Odontologia. Biossegurança. Riscos Ocupacionais. Coronavírus.

\section{INTRODUÇÃO}

Acidentes com materiais perfurocortantes regularmente envolvem agentes biológicos patogênicos capazes de causar doenças, devido à presença de bactérias, vírus e fungos ${ }^{1}$. Os cirurgiões-dentistas estão vulneráveis, uma vez que há alto risco de contaminação por doenças transmissíveis durante $\mathrm{o}$ atendimento, como 
influenza, pneumonia, hepatites $\mathrm{B}$ e $\mathrm{C}$, conjuntivite, herpes, tuberculose, sífilis, síndrome da imunodeficiência adquirida (HIV/Aids) ${ }^{2}$ e, atualmente, a coronavirus disease (COVID-19) ${ }^{3}$.

Os profissionais da saúde estão expostos aos mais diversos riscos ocupacionais durante a sua jornada de trabalho, sendo eles físicos, químicos, mecânicos, psicossociais ou biológicos ${ }^{4}$. Na Odontologia os trabalhos estão sujeitos a inúmeras formas de contaminação, devido à utilização de instrumentos perfurocortantes e equipamentos que produzem aerossóis, assim como pelo contato com fluídos corporais ${ }^{4}$.

Os atendimentos por acadêmicos de Odontologia os deixam expostos aos riscos ocupacionais de forma semelhante aos profissionais da área, por realizarem diversos procedimentos com diferentes níveis de complexidade, porém com habilidade técnica em desenvolvimento $^{6}$, apresentando índice mais elevado de acidentes quando comparados aos acadêmicos dos cursos de Farmácia, Enfermagem e Medicina ${ }^{7}$.

A alta prevalência de acidentes ocupacionais entre acadêmicos de Odontologia é preocupante ${ }^{1}$. É necessário observar com bastante atenção a exposição ao material biológico nas clínicas-escola de Odontologia ${ }^{8}$ e uso de medidas preventivas específicas, como a vacinação contra Hepatite B, tríplice viral e dupla tipo adulto, a lavagem das mãos, a desinfecção e esterilização dos instrumentais e o uso de equipamentos de proteção individuais completos e adequados ${ }^{1}$, desinfetar as superfícies, utilizar barreiras físicas nos equipamentos, manter as caixas de descarte em locais visíveis e descartar adequadamente os resíduos gerados ${ }^{8}$.

Desta forma, os acidentes ocupacionais devem ser prevenidos e analisados tanto no ambiente profissional como entre os estudantes universitários por meio da divulgação de métodos que ressaltem a importância da biossegurança, o manuseio correto dos instrumentos e materiais biológicos, a imunização completa e como proceder em casos de acidentes 9 .

Este estudo teve o objetivo de avaliar o índice de ocorrências e as características dos acidentes envolvendo materiais perfurocortantes entre acadêmicos do curso de Odontologia da Universidade Estadual do Piauí (UESPI), Campus Professor Alexandre Alves Oliveira, Parnaíba.

\section{MÉTODOS}

Todos os procedimentos deste estudo seguiram os princípios éticos estabelecidos pela legislação em vigor, sendo o projeto aprovado pelo Comitê de Ética em Pesquisa da UESPI sob o número do parecer 1.643.862.

Delineou-se um estudo transversal, descritivo, com abordagem quantitativa, realizado com estudantes do curso de Odontologia da UESPI, Campus Professor Alexandre Alves Oliveira, Parnaíba. Foram incluídos acadêmicos devidamente matriculados em atividades da clínica odontológica, a partir do $5^{\circ}$ período.

$O$ instrumento para a coleta de dados consistiu em questionário semiestruturado autoaplicável e padronizado, elaborado pelos pesquisadores, abordando o histórico de acidentes perfurocortantes durante as atividades clínicas; conhecimento das condutas imediatas profiláticas pós-acidente; conhecimento, percepção do risco e esclarecimentos formalmente preconizados $\mathrm{e}$ medidas de proteção.

O tempo de aplicação do questionário foi de aproximadamente 15 minutos. Os dados foram tabulados e analisados por meio de estatísticas descritivas.

\section{RESULTADOS}

Do total de estudantes matriculados em atividade clínica $(n=58)$, seis não aceitaram participar da pesquisa, ficando a amostra final com 
52 participantes. Acidentes foram relatados por 15 $(28,85 \%)$ alunos, sendo $10(66,66 \%)$ do quinto período, $04(26,67 \%)$ do sétimo período e 01 $(6,67 \%)$ do nono. Esclarece-se que a instituição promove apenas uma entrada/ano, o que resulta em alternância de blocos por semestre.

$\mathrm{O}$ maior número de acidentes ocorreu nas disciplinas de Cirurgia ( $\mathrm{n}=6,40 \%)$, Endodontia $(\mathrm{n}=5,33,33 \%)$, Dentística Restauradora ( $\mathrm{n}=2$, 13,33\%), Dentística Operatória $(n=1,6,67)$ e Periodontia $(n=1,6,67)$.

Observou-se que $32 \quad(61,53 \%)$ dos acadêmicos afirmaram haver deficiência teórica em relação às condutas a serem tomadas em casos de exposição acidental a materiais perfurocortantes contaminados. Na pesquisa realizada na UESPI apenas 3 (20\%) dos acadêmicos comunicaram o acidente, mas ainda assim, o fizeram ao professor da disciplina e não aos órgãos competentes.

Em relação ao instrumental/material envolvido no acidente, a sonda exploradora foi o que causou mais causou acidentes $(n=7,46,67 \%)$, seguido pela agulha $(n=4,26,67 \%)$ e pela lima endodôntica ( $n=2,13,34 \%)$; ao passo que brocas e curetas foram responsáveis por $1(6,66 \%)$ acidente cada. Do total de acidentes, metade ocorreu durante $\mathrm{o}$ atendimento ao paciente e metade durante a lavagem de instrumental.

\section{DISCUSSÃO}

A biossegurança propõe aos profissionais e acadêmicos medidas e práticas para que possam desenvolver com segurança as atividades laborais, diminuindo ou eliminando os riscos inerentes aos atendimentos clínicos, de modo a preservar a saúde dos envolvidos ${ }^{10}$. O risco de acidentes ocupacionais entre acadêmicos de Odontologia pode estar associado ao estado emocional frente ao atendimento, pressa para finalizar o procedimento, inexperiência para manusear itens e instrumentos odontológicos, desconhecimento das normas de biossegurança ou negligência aos riscos da exposição. Os alunos de graduação sofrem até duas vezes mais acidentes do que os cirurgiões-dentistas graduados há dez anos ${ }^{11}$.

Mesmo com disciplinas moduladoras da conduta do futuro profissional, ainda ocorrem acidentes com materiais perfurocortantes, resultado da falha no cuidados em biossegurança, fato este preocupante, pois mesmo com pouco tempo de atividade clínica, de cada quatro alunos, aproximadamente um já esteve exposto a material biológico potencialmente contaminado, o qual pode ocasionar doenças que oferecem risco à vida, como hepatite, HIV/Aids ${ }^{12}$ e COVID- $19^{7}$.

$\mathrm{Na}$ literatura encontrou-se o maior número de acidentes em clínica integrada, seguida por Cirurgia, Dentística, Endodontia e Prótese Clínica ${ }^{6}$, concordando em parte com este estudo, que observou haver mais acidentes nas disciplinas de Cirurgia e Endodontia.

A inexperiência por parte do acadêmico pode de alguma forma contribuir para que ocorram incidentes com perfurocortantes, pois acidentes estão relacionados ao pico de ansiedade, devido ao atendimento aos pacientes, carga horária elevada, inexperiência, estresse, pouco campo de visão, falta de atenção à biossegurança e a falta de habilidade ${ }^{13}$. Essa afirmação se comprova ao passo que a maioria dos acidentes aconteceram no primeiro semestre de atendimento clínico, nos quais a vivência clínica foi insuficiente para garantir uma maior segurança aos estudantes. Hbibi et al. (2018) ${ }^{14}$, também observaram que a maior frequência de acidentes ocorreu entre os acadêmicos do primeiro ano de clínica.

Identificou-se que $32 \quad(61,53 \%)$ dos acadêmicos apresentam deficiência teórica em relação às condutas a serem tomadas em casos de exposição acidental com materiais perfurocortantes contaminados, conduta esta que se inicia com a notificação formal em ficha padronizada que visa exemplificar a característica deste incidente com perfurocortantes, concordando com estudo de 
Hbibi et al. (2018) ${ }^{14}$ e Armond et al. (2016) ${ }^{19}$, que verificaram que acadêmicos não sabiam se portar diante a um acidente com material biológico e/ou tinham pouco conhecimento sobre gerenciamento e os riscos dos acidentes laborais.

No presente estudo apenas 3 (20\%) acadêmicos comunicaram o acidente, mas o fizeram ao professor da disciplina e não aos órgãos competentes, em desacordo com preconizado pelo Ministério da Saúde, que traz como orientação a ser seguida nas instituições de saúde de todo o país, que acidentes de trabalho com sangue e outros fluidos potencialmente contaminados sejam tratados como casos de emergência médica ${ }^{15}$. Essa situação coincide com a de outros estudos que indicam que muitos acadêmicos e até mesmo profissionais não notificam ou não seguem o protocolo pós-exposição ${ }^{16}$.

$\mathrm{Na}$ literatura, os acidentes ocorrem durante o atendimento clínico e esterilização, os instrumentais mais mencionados são agulhas anestésicas, curetas periodontais, sondas exploradoras e brocas $^{13}$, concordando com resultados encontrados nesta pesquisa.

Observa-se, portanto, que há necessidade de se implementar ações educativas permanentes com ênfase em prevenção, conscientização e acompanhamento dos casos de acidentes laborais, além disso, aprimorar as práticas preventivas e realizar treinamentos periódicos ${ }^{17}$. As precauçõespadrão são formas de prevenção a serem empregadas na utilização de barreiras ou uso dos equipamentos de proteção individual de assistência a todos os pacientes, prevenção na manipulação de sangue, secreções e excreções e contato com mucosas e pele não-íntegra, prevenção de acidentes perfurocortantes, manejo adequado em procedimentos de descontaminação e descarte ${ }^{18}$. Acidentes com exposição a materiais contaminados devem receber mais atenção na reformulação de protocolos de biossegurança para que sejam mais completos e didáticos dentro da própria instituição, para adequada capacitação dos profissionais em formação ${ }^{19}$.

\section{CONCLUSÃO}

Constatou-se que, mesmo havendo disciplinas que abordam conteúdos de biossegurança, um número considerável de acadêmicos já se acidentou com material perfurocortante. Os dados apontam que os acidentes ocorreram com estudantes do quinto período e nas disciplinas de Cirurgia e Endodontia.

\section{ABSTRACT \\ Accidents with cutting and piercing materials among Dentistry students}

Health professionals are exposed to the most diverse occupational risks during their workday and dentists lead the number of accidents with biological materials. The assistance provided by dental students leaves them exposed to occupational risks in a similar way to professionals in the field. This study aimed to evaluate the prevalence and characteristics of accidents with cutting and piercing instruments among students of a Dentistry course. There was a prevalence of $28.85 \%$ of accidents, with the highest percentage in the 5th period of the course, mainly in the Surgery and Endodontics clinics. Only $20 \%$ of those affected reported the occurrence and the sickle probe was the instrument most involved. In addition, accidents occurred equally in patient care and washing of instruments. Therefore, it is necessary to invest in permanent educational and normative actions to raise the awareness of students about needlestick injuries.

Descriptors: Students, Dental. Biosafety. Occupational Risks. Coronavirus.

\section{REFERÊNCIAS}

1. Mazutti WJ, Freddo SL, Lucietto DA. Acidentes perfurocortantes envolvendo material biológico: o dizer e o fazer de estudantes de um curso de graduação em 
Odontologia. Rev ABENO. 2018;18(4):2130.

2. de Santana Costa P, de Matos SMS, de Melo TRNB, Rodrigues HB. Avaliação dos acidentes com instrumentais perfurocortantes entre os Cirurgiões-Dentistas. Res Soc Dev. 2020; 9(8):e633986149.

3. Ather A, Patel NB, Diogenes A, Hargreaves K. Coronavirus Disease 19 (COVID-19): Implications for Clinical Dental Care. J Endod. 2020; 46(5):584-95.

4. Pedrosa MEHC, Donato MAM, de Andrade HF. Acidente de trabalho com material perfurocortante envolvendo profissionais na área de saúde. Cad Grad Ciênc Biol Saúde. 2019; 4(2):13.

5. de Lima AEC, Moura ASA, Aragão MMMS, Barbosa FCB. Frequência de acidentes perfurocortantes em dentistas de SobralCE. Cadernos ESP. 2020; 14(1):50-5.

6. Martins MES, Fernandes TCB, Lyrio-Alvares MCN. Estudo dos acidentes com instrumentos perfurocortantes em clínica de graduação em odontologia. Rev Fac Odontol Porto Alegre. 2020; 61(1):61-8.

7. de Paiva SN, Zaroni WCS, Leite MF, Bianchi PR, Pereira TCR. Acidentes ocupacionais com material biológico em Odontologia: uma responsabilidade no ensino. Rev ABENO. 2017; 17(3):76-88.

8. da Costa Teixeira D, de Oliveira JD, Corrêa AKM. Avaliação da conduta de biossegurança na prática clínica entre acadêmicos do curso de odontologia-revisão de literatura. Braz J Dev. 2020; 6(12):100782-8.

9. Andrade RRA, Almeida RAC, Sampaio GC, Pereira JRD, Andrade ESS. Ocorrência de acidentes com instrumentais pérfuro-cortantes em clínica odontológica na cidade do RecifePernambuco: Estudo-piloto. Rev Cir Traumatol Buco-Maxilo-Fac. 2013;13(2):87100.
10. Mazzutti WJ, Lucietto DA, Freddo SL. Nível de informação de estudantes de odontologia sobre riscos, prevenção e manejo de acidentes com perfurocortantes. Rev Rede Cuid Saúde. 2018;12(2):17-27.

11. Trezena S, Sarmento TS, Cruz BSR, Mendes PB, Santos ASF, Costa SM, et al. Medidas de precaução padrão adotadas em uma clínica escola de graduação em Odontologia. HU Rev. 2019; 45(2):148-55.

12. Binalrimal S, AlDrees A, AlWehaibi M, AlAsmary M, AlShammery A, AlHaidri E, et al. Awareness and compliance of dental students and interns toward infection control at Riyadh Elm University. GMS Hyg Infect Control. 2019; 14:Doc10.

13. Alencar TLN. Acidentes com material perfurocortante na prática odontológica. (Trabalho de Conclusão de Curso). Centro Universitário São Lucas, Roraima, 2019.

14. Hbibi A, Kasouati J, Charof R, Chaouir S, El Harti K. Evaluation of the knowledge and attitudes of dental students toward occupational blood exposure accidents at the end of the dental training program. J Int Soc Prevent Communit Dent. 2018, 8(1):77-86.

15. Rapparini CL, Vitória MAA, Lara LTR. Recomendações para atendimento e acompanhamento de exposição ocupacional a material biológico: HIV e hepatites B e C. 2010. [Acesso em 7 abr. 2020]. Disponível em: http://bvsms.saude.gov.br/bvs/publicacoes 104manual_acidentes.pdf.

16. Trezena S, Farias LPM, Barbosa GFA, Costa SM, Barbosa Jr ES, Pinto MQC. Práticas em biossegurança frente aos acidentes ocupacionais entre profissionais da odontologia. Arq Odontol. 2020; 56:e07.

17. Fernandes LHF, Nunes WB, Silva LC, Wanderley RL, Barros CMB, Cavalcanti AL. Needlestick and sharp instruments injuries among Brazilian dentistry students. Contemp 
Clinl Dent. 2017; 8(1):112-5.

18. de Melo TRNB, Costa PS, Oliveira VS, Diniz MAG, Oliveira Jr AG. Avaliação do controle das medidas de biossegurança adotadas por acadêmicos de Odontologia. REAC. 2020; 8:e2112.
19. Armond ACV, Gonçalves PF, Flecha OD, de Oliveira DWD, Sampaio FC, Falci SGM. Conhecimentos de biossegurança para as principais atividades de risco envolvendo servidores públicos, discentes e empregados da limpeza do curso de Odontologia da UFVJM/Diamantina. RBOL. 2016; 3(2):3252.

\section{Correspondência para:}

Daniela Andrisia Teixeira Messias

e-mail: danielaandrisia@gmail.com

Curso de Odontologia UESPI

Av. Nossa Senhora de Fátima s/n

64.202-220 Parnaíba/PI 